\title{
Cyclic Loading Test for the Small-Strain Shear Modulus of Saturated Soft Clay and Its Failure Mechanism
}

\author{
Zhende Zhu $\mathbb{D}^{1,2}$ Cong Zhang ${ }^{\mathbb{D}}{ }^{1,2}$ Jun Wang, ${ }^{3}$ Peng Zhang, ${ }^{4}$ and Duan Zhu ${ }^{1,2}$ \\ ${ }^{1}$ Key Laboratory of Ministry of Education for Geomechanics and Embankment Engineering, Hohai University, \\ Nanjing 210098, China \\ ${ }^{2}$ Jiangsu Research Center for Geotechnical Engineering Technology, Hohai University, Nanjing 210098, China \\ ${ }^{3}$ College of Architecture and Civil Engineering, Wenzhou University, Wenzhou, Zhejiang 325035, China \\ ${ }^{4}$ Huadong Engineering Corporation Limited, Hangzhou 310014, China \\ Correspondence should be addressed to Cong Zhang; zhangcong999@hhu.edu.cn
}

Received 11 April 2021; Revised 6 May 2021; Accepted 5 June 2021; Published 22 June 2021

Academic Editor: Bin Gong

Copyright (C) 2021 Zhende Zhu et al. This is an open access article distributed under the Creative Commons Attribution License, which permits unrestricted use, distribution, and reproduction in any medium, provided the original work is properly cited.

Small-strain shear modulus, $G_{\max }$, is a key evaluation index to study the dynamic characteristics of soil in geotechnical engineering. It is widely adopted to evaluate the stiffness of soft soil in soil dynamic engineering. In this paper, the cyclic triaxial tests and resonance column tests were carried out to explore the variation of $G_{\max }$ of soft clay with respect to various confining stresses, cyclic shear stress ratios, pore pressures, and effective stress paths. Test results indicated that the effective stress decreased gradually with the increase of the cycle shear stress ratio. The failure points were mainly concentrated in a rectangular area, defined by the normalized effective stress from 0.56 to 0.64 and the normalized shear modulus from 0.72 to 0.78 . Additionally, a short pause caused a small increase of $1-2 \%$ in $G_{\max }$ as well as pore pressure. This study demonstrates that $G_{\max }$ can be effectively used to characterize the failure of saturated soft clay in a more intuitive and convenient way, compared to the commonly used strain failure standards.

\section{Introduction}

Soft clay is found in coastal plains, estuary deltas, lake basins around, mountain valleys, and other areas, most of which belong to the middle or late Fourth Age. Figure 1 shows the clay content of China. In general, soft clay has the characteristics of low carrying capacity, shallow water table, high water content, high compression, sensitivity, and large touch degeneration. These characteristics have a very negative impact on the long-term stability and normal operation of the upper structure [1]. That is why it is a subject that people have been interested in for decades [2-6]. The small-strain shear modulus $\left(G_{\max }\right)$ is a key evaluation index in the seismic design and performance of geotechnical disciplines. As a fundamental property of the soil, accurate estimation and determination of $G_{\max }$ is an important aspect of scientific and rational calcu- lation and evaluation of liquid phase reaction, earthquakeinduced deformation, and dynamic and static soil structure interactions [7].

For soft clay, soil destruction is a complex and cumulative process defined by strain as a standard of destruction (in general, it is 5 or 10\%) [8]. Hyodo et al. [9] proposed the destruction criteria based on the cycle stress ratio (CSR) to explain that most relationship curves of soft clay had a distinct inflection point, and this inflection point corresponds to the strain as a destructive strain. Hyde et al. [10] presented a set of destruction criteria based on the extreme state of the active stress path. That is, the strain value corresponding to the effective stress path reaching the static failure limit state line can be used as the standard of destruction in uniaxial loading. Lei et al. [11] put forward the destruction standard of soft clay, by showing that the strain development of soft clay had a clear 


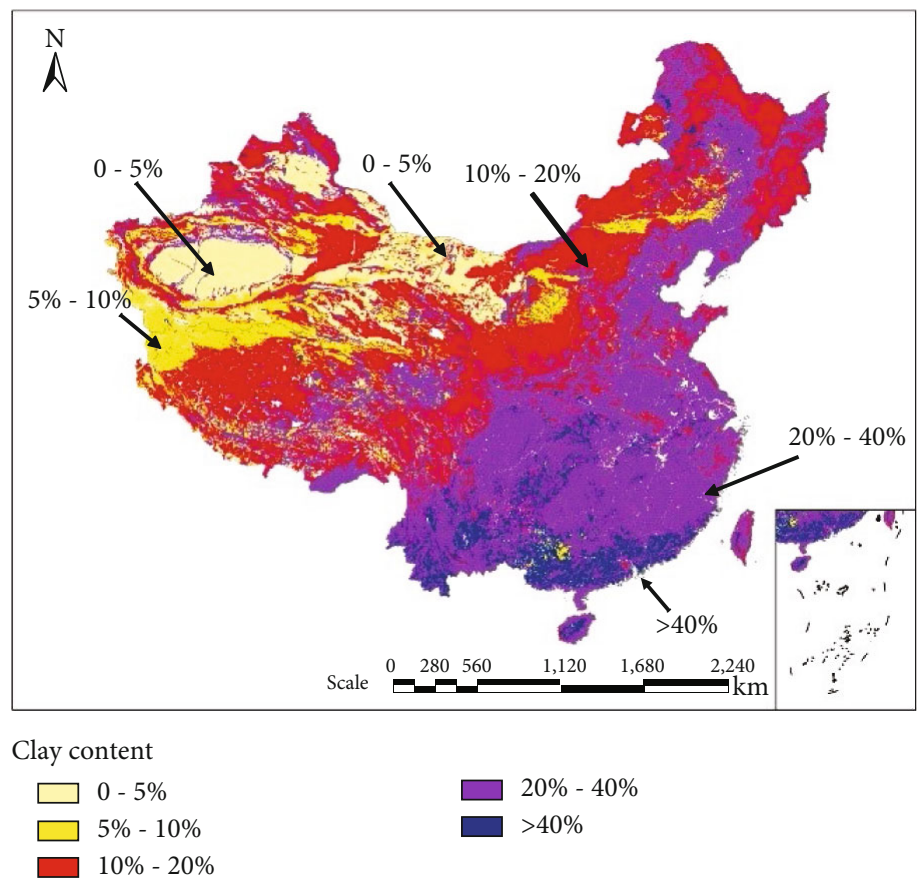

Figure 1: Clay content of China [12].

inflection point in the coordinate space of $\varepsilon-\log N$, and all the inflections were in a straight line. Thus, there is no uniform standard for the destruction of soft clay under dynamic load. Therefore, we judge the change of the soft clay structure based on the change of $G_{\max }$.

The undrained triaxial tests were performed by Shirley and Hampton [13] to explore the stress-state dependency of $G_{\max }$ under a constant void ratio (e). The results indicated that the stress-strain hysteretic loop, resilient modulus, and permanent strain were significantly dependent on the confining stress and the cyclic stress ratio (CSR). Thammathiwat and Chim-Oye [14] employed the cyclic triaxial test to study the interaction between the cyclic strength and the pore pressure of undisturbed Bangkok clay under various confining stresses, frequencies, and stress ratios. Meanwhile, several researchers have developed an uniaxial shear test instrument with multidirectional and looping capabilities to study the dynamic characteristics of soft clay [15-17]. These studies demonstrated that the dynamic shear modulus decreased, and the cyclic strain accumulation increased with an increase in CSR [18]. Besides, as the strain increased, the dependence of the modulus on the direction of the stress path decreased, and shear strain and volume strain also increased [19-21].

Many indoor tests have been carried out and widely used to study the stress-strain properties of soil at small shear strain levels/amplitudes $(\gamma<0.01 \%)$, for example, resonant column, bender elements, torsional shear tests, and cyclic triaxial tests [22-24]. Darabi et al. [25] conducted the cyclic triaxial tests of variable circumference pressure (VCP) to draw that the coupling of cycle deviatoric and circular confining stress can simulate the combination of cyclic shear stress and cyclic normal stress components. Compared to the resonant column device employed by Aggour and Zhang [26], stress and displacement were seen as control variables that control cyclic loadings. According to the recorded acceleration calculation of the time and orbit of the shear strain, it can be clearly seen that seismic effect is produced by multidirectional shear strain [27, 28]. It was carried out by Bowman and Soga [29] about experimental research on the shear modulus for temporal change effects based on various test materials such as indoor clean sand and Gulf of Mexico soft clay. The results were shown that under constant confining stress, the law of shear modulus growth varied for different material tests, while the shear modulus gradually increased with time.

In spite of many studies dealing with the characterization of soft clay, the change law of $G_{\max }$ is still not clearly known. More importantly, the deformation laws and criteria are not yet perfectly known under cyclic loads. There are numerous factors that affect the determination of $G_{\max }$. Moreover, due to sample disturbance and long consolidation time, the effect of time is often ignored, which could result in large errors. As a consequence, the parameters determined by laboratory tests cannot be directly used in engineering practice.

To address the above problems, we first prepared the soft clay samples and measured the physical indexes (Section 2) and described the test instrument and system parameters in Section 3. Then, we investigated the impact of cyclic loads on $G_{\max }$ of saturated soft clay. The dynamic characteristics of soft clay were studied under different CSRs. Factors influencing the attenuation of $G_{\max }$ were examined, and failure criteria of intact saturated soft clay on the basis of $G_{\max }$ are determined in Section 4. The conclusions drawn from the experimental work and computational analysis done in this research are presented in the last section. 


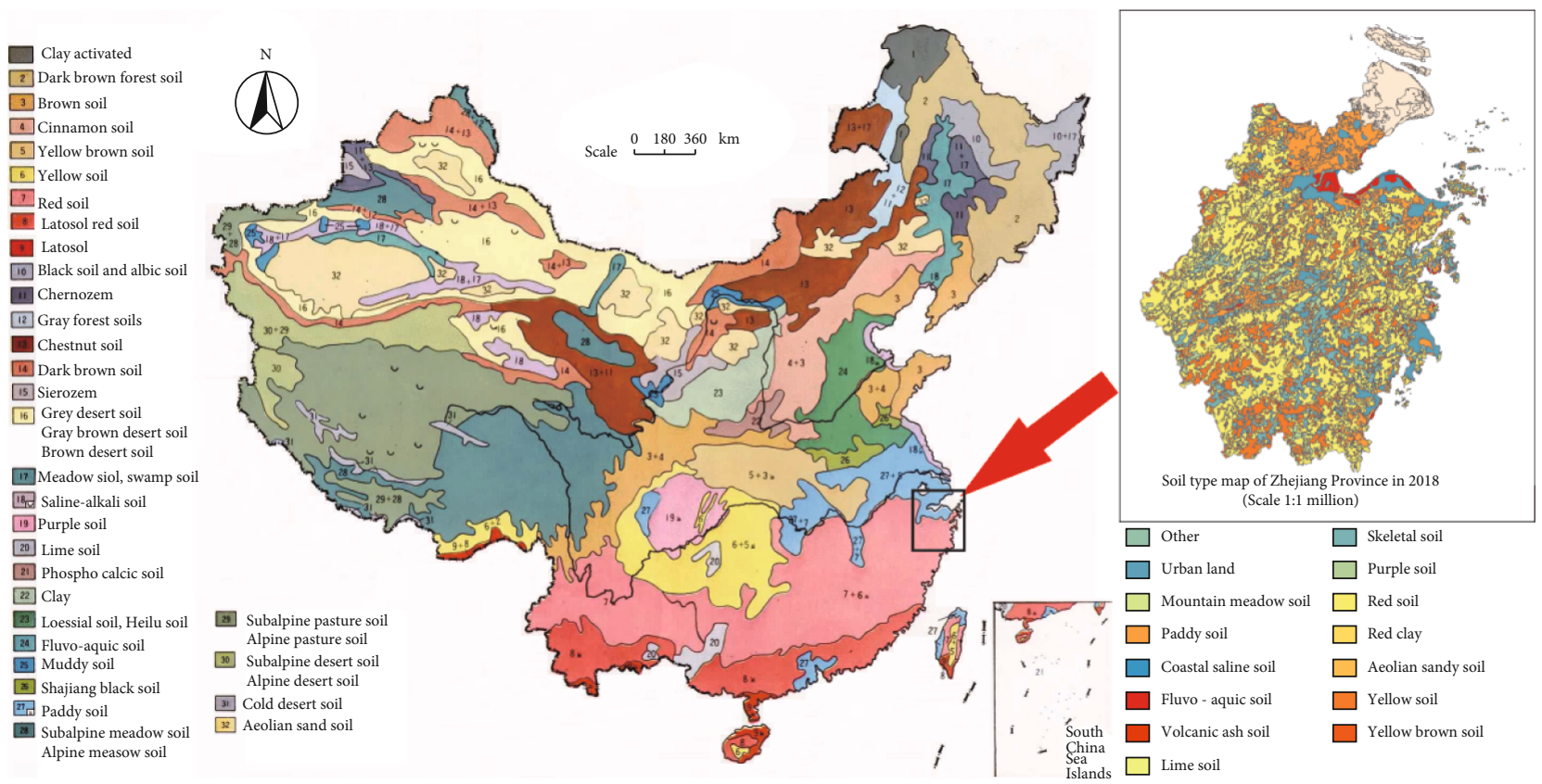

FIgUre 2: Soil distribution maps within China and in Zhejiang Province [12].

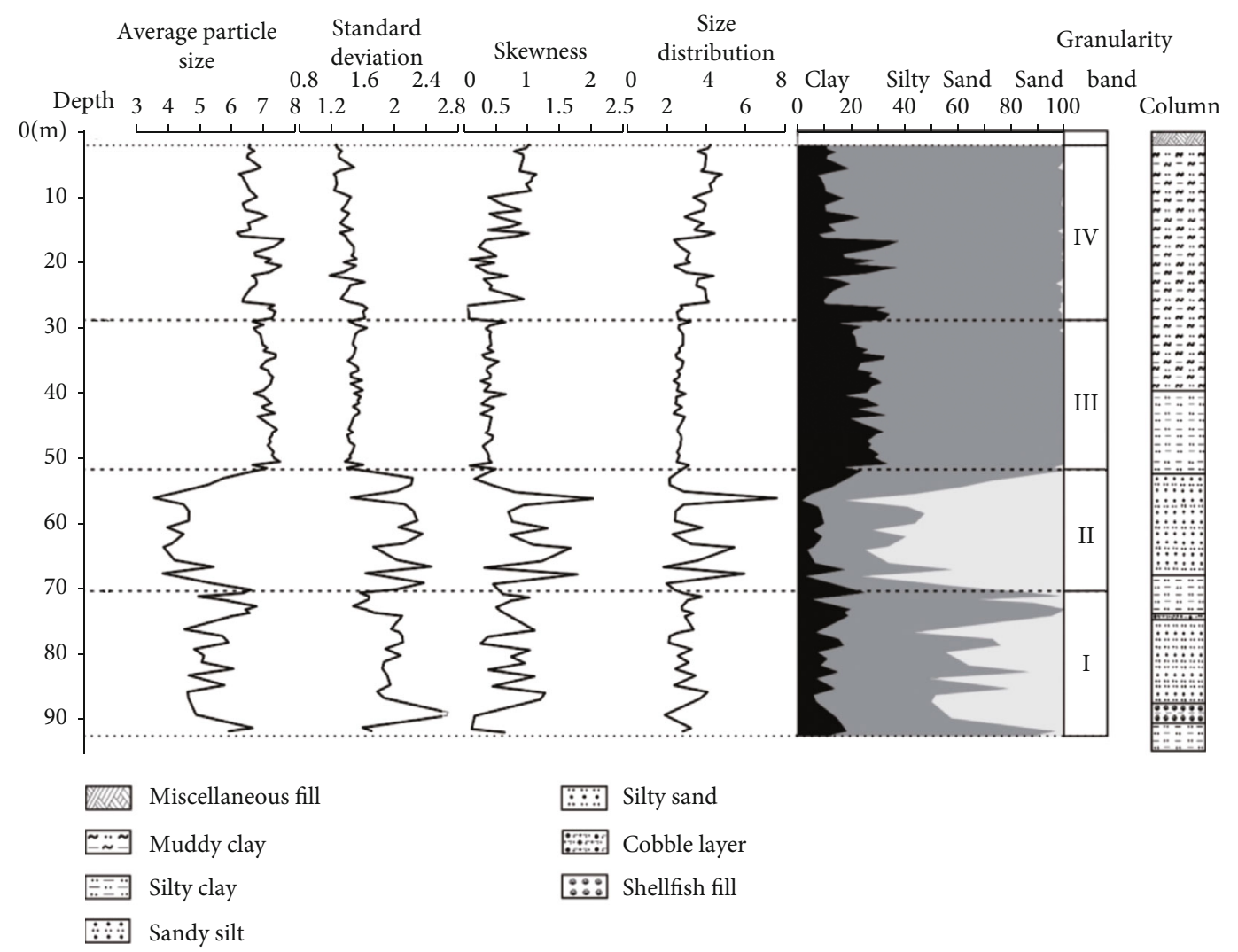

Figure 3: The stratigraphic map of Wenzhou, Zhejiang Province [30]. 
TABLE 1: Mechanical parameters and values [31].

\begin{tabular}{lccccccc}
\hline Soil parameter & $\rho\left(\mathrm{g} / \mathrm{m}^{3}\right)$ & $\omega(\%)$ & $\omega_{p}(\%)$ & $\omega_{L}(\%)$ & $I_{p}$ & $P_{c}(\%)$ & $F_{c}(\%)$ \\
\hline Value ranges & $1.7 \sim 1.75$ & $42 \sim 50$ & 26 & 57 & 31 & 54.3 & 94.6 \\
\hline
\end{tabular}

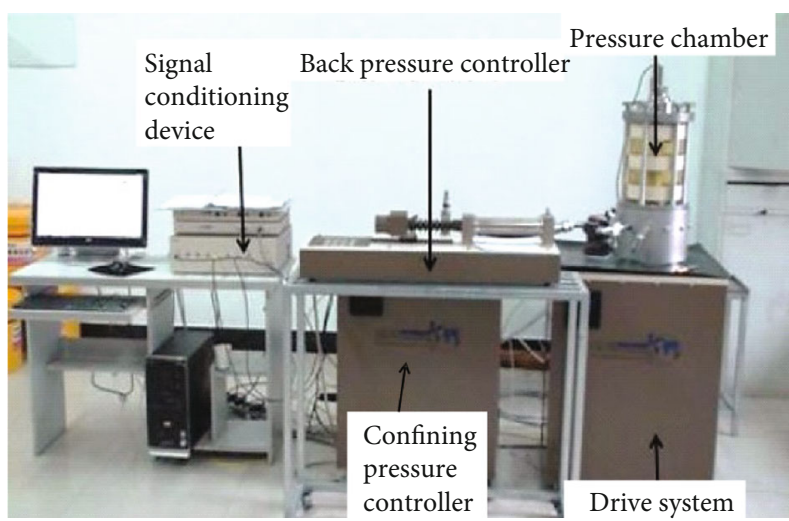

(a)

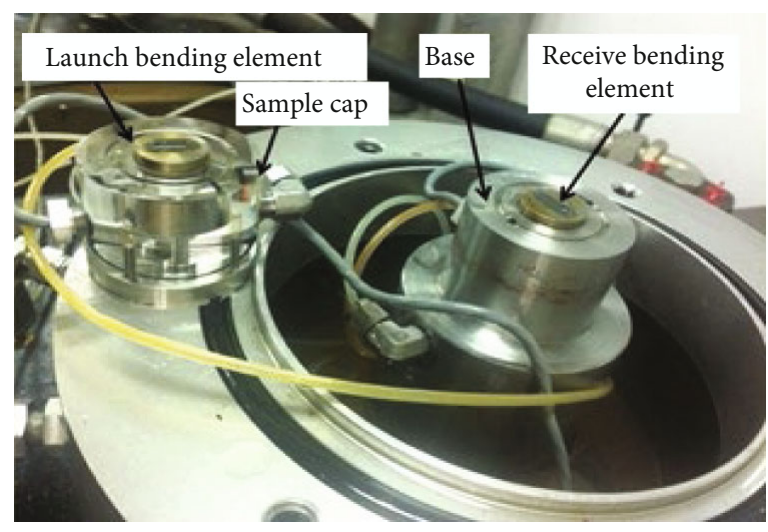

(b)

FIgURE 4: GDS dynamic triaxial test system (a) and bending element test system (b).

TABLe 2: The test items and accuracy of the dynamic triaxial test system.

\begin{tabular}{lccc}
\hline No. & Test items & Range value & Accuracy \\
\hline 1 & Axial displacement & $100 \mathrm{~mm}$ & Measurement resolution reaches $0.08 \mu \mathrm{m}$ \\
2 & Axial stress & $2 \mathrm{kPa}$ & Accuracy can reach $0.1 \%$, that minimum resolution is $0.2 \mathrm{kPa}$ \\
3 & Confining stress range & $3 \mathrm{MPa}$ & Accuracy reaches $1 \mathrm{kPa}$ \\
4 & Back pressure range & $2 \mathrm{MPa}$ & Accuracy reaches $1 \mathrm{kPa}$ \\
\hline
\end{tabular}

\section{Sampling and Physical Properties}

Soft clay in the test was derived from the Chashan Higher Education Park, Wenzhou University. Soil distribution maps within China and in Zhejiang Province are depicted as Figure 2, and the stratigraphic map is illustrated in Figure 3.

The soil depth is $5-7 \mathrm{~m}$, which is typical for the marine soft clay on the southeast coast of China [31]. In order to obtain a sample of the intact soil with fewer disturbances, the thinwalled pipe cutting method was adopted to decrease the disturbance of intact soft clay. The soil collector was a thinwalled PVC pipe (diameter $\times$ height : $160 \mathrm{~mm} \times 300 \mathrm{~mm}$ ). Both ends of the PVC pipe were sealed with wax and maintained in the constant temperature and humidity incubator. To shorten the consolidation drainage time of the samples, round filter paper pieces were attached on the upper and lower ends of the samples, and filter paper was attached on the side and connected to the top filter. After saturation for $24 \mathrm{~h}$, the value of $B$ was set to 0.97 as the saturation completion criterion. The consolidation test was based on the excess pore water pressure dropping to 0 and displacement of less than $60 \mathrm{~mm}^{3} / \mathrm{h}$ as the standard. The mechanical parameters of soft clay are given in Table 1.

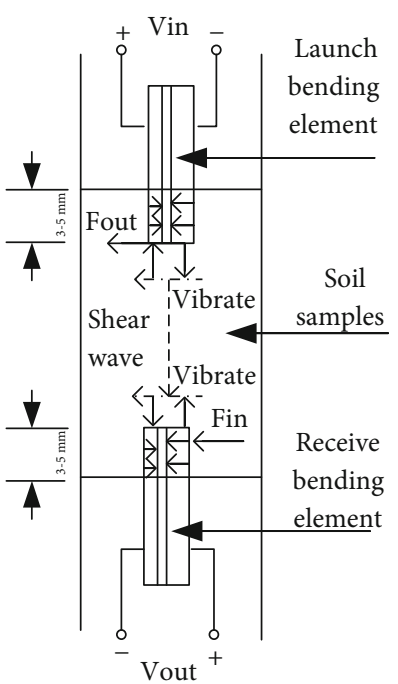

FIGURE 5: Working principle of shear wave velocity tested by bending element [32]. 
TABle 3: The test scheme design.

\begin{tabular}{|c|c|c|c|c|}
\hline No. & $\sigma_{m}(\mathrm{kPa})$ & $f(\mathrm{~Hz})$ & CSR & Cyclic strain (\%) \\
\hline 1 & 50 & 0.02 & 0.476 & - \\
\hline 2 & 50 & 0.02 & 0.551 & - \\
\hline 3 & 50 & 0.02 & 0.625 & - \\
\hline 4 & 100 & 0.02 & 0.489 & - \\
\hline 5 & 100 & 0.02 & 0.516 & - \\
\hline 6 & 100 & 0.02 & 0.571 & - \\
\hline 7 & 100 & 0.02 & 0.625 & - \\
\hline 8 & 200 & 0.02 & 0.362 & - \\
\hline 9 & 200 & 0.02 & 0.392 & - \\
\hline 10 & 200 & 0.02 & 0.447 & - \\
\hline 11 & 200 & 0.02 & 0.517 & - \\
\hline 12 & 300 & 0.02 & 0.432 & - \\
\hline 13 & 300 & 0.02 & 0.472 & - \\
\hline 14 & 300 & 0.02 & 0.569 & - \\
\hline 15 & 100 & 0.02 & - & 0.5 \\
\hline 16 & 100 & 0.02 & - & 1 \\
\hline 17 & 100 & 0.02 & - & 2 \\
\hline 18 & 200 & 0.02 & - & 0.75 \\
\hline 19 & 200 & 0.02 & - & 2 \\
\hline 20 & 200 & 0.02 & - & 3 \\
\hline
\end{tabular}

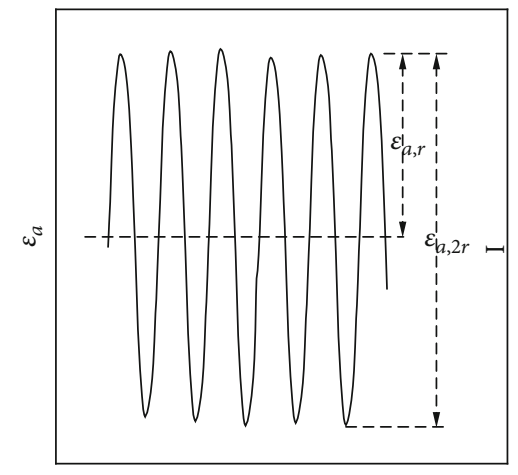

(a)

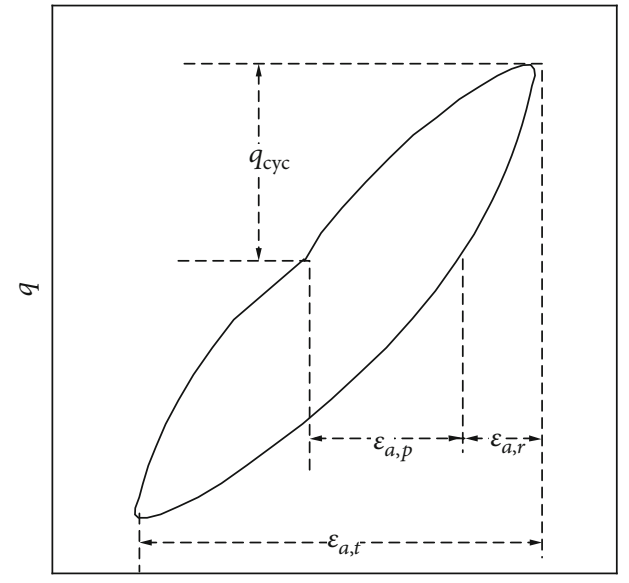

(b)

FIgURE 6: Curves of biaxial cycling obtained from the triaxial test results: strain development curve with cycle time (a) and a typical hysteresis (b).

\section{Test Apparatus and Parameters}

The tests are carried out using a combination of cyclic triaxial test system and piezoelectric ceramic bender element system developed by GDS, UK [31]. The dynamic triaxial test system can be used to do both static and dynamic tests. It includes five important components, as shown in Figure 4(a). The test items and accuracy of the test instrument are presented in Table 2. The piezoelectric ceramic bending element test system includes four key components, which are shown in Figure 4(b).
The test control and data recording of the dynamic triaxial test system are recorded in real time by the GDSLAB software, which can achieve the conventional triaxial compression test, the stress-controlled dynamic triaxial test, and the straincontrolled dynamic triaxial test. The method of bending element test is a simple and intuitive method with a clear principle. It is noted that the combination device used in this study can improve the accuracy of the wave velocity. Soil is a particle material and has a variety of contact forces-deformation behavior. When a point in the soil is stressed by the release 


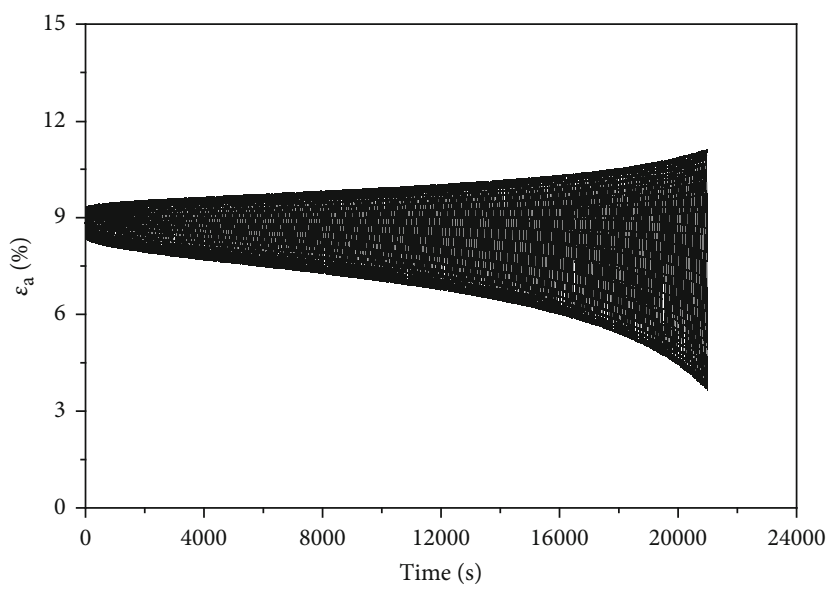

- $\operatorname{CSR}=0.392$

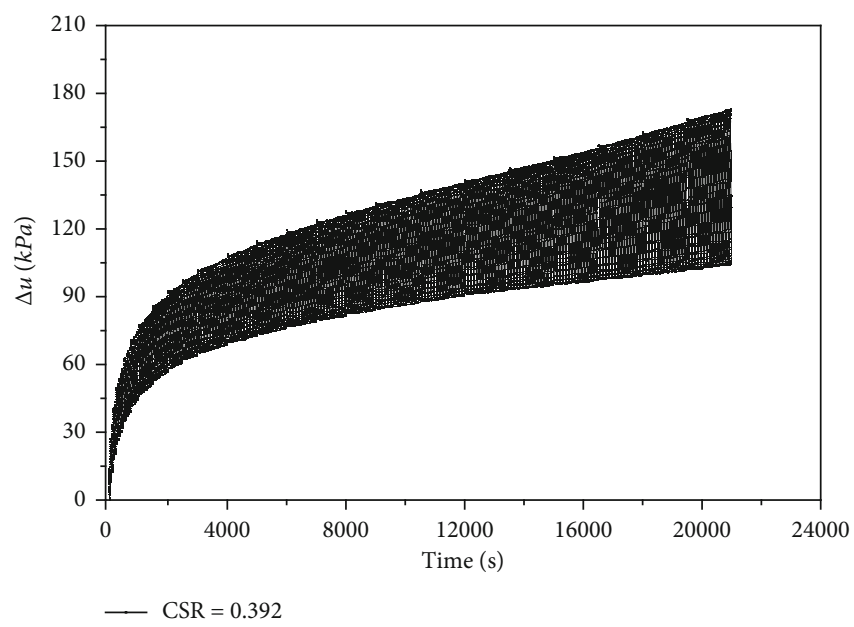

(b)

FIGURE 7: Strain and pore pressure curve under $200 \mathrm{kPa}$ confining stress: strain curve (a) and pore pressure (b).

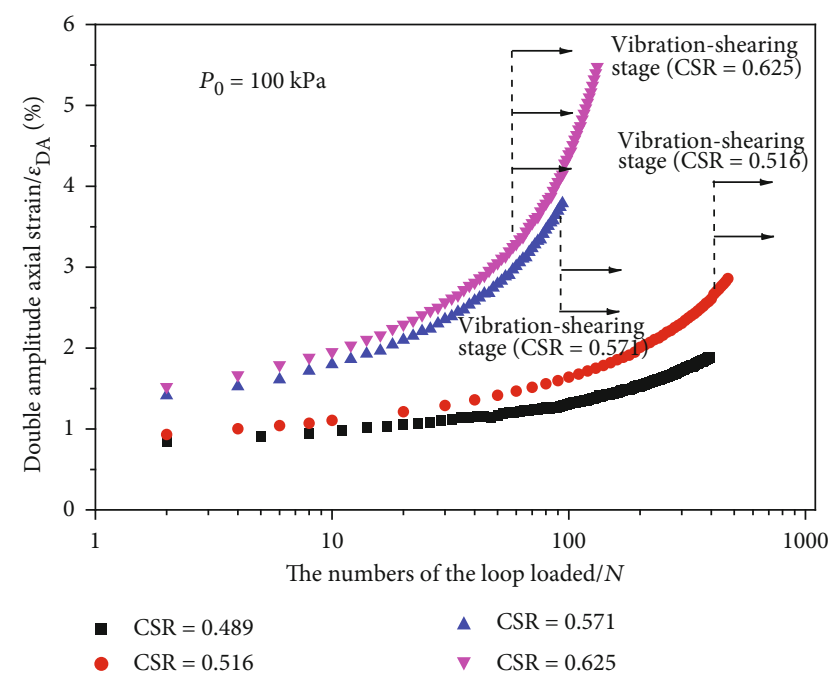

(a)

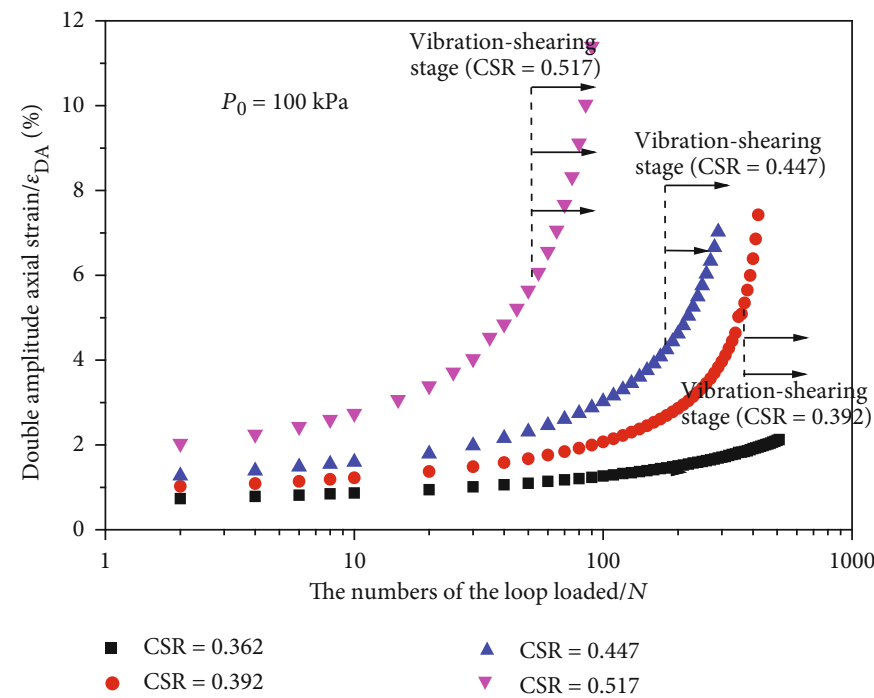

(b)

Figure 8: Curves of dynamic strain and different cyclic stress ratios: $100 \mathrm{kPa}(\mathrm{a}) ; 200 \mathrm{kPa}(\mathrm{b})$.

of energy, a small strain will spread in the condition of elastic waves. The velocity of elastic wave depends on the elastic modulus of the soil. Therefore, if it can be measured for the small-strain elastic wave and velocity, the elastic parameters of the soil can be determined.

Figure 5 is the schematic shear wave velocity test of the soil sample by the bending. During the soil shear wave velocity test, the emission bending and receiving bending must be inserted into both ends of the soil. Then, the voltage pulse of the excitation signal at the specific frequency will be transmitted by the emission bending and be received by receiving bending. The vibrations generated by the shear wave are transformed into electrical signals. The signals are stored, and then, the propagation time $\left(t_{s}\right)$ of the shear wave is obtained by the signal comparison. The shear wave velocity $\left(V_{s}\right)$ and shear modulus can be calculated by the distance of propagation $(L)$.

\section{Impact of Cyclic Loads on $G_{\max }$ of Saturated Soft Clay}

4.1. Test Method. Dynamic tests are performed using two methods: (1) Stress control: a certain number of constant amplitude cyclic load stress are imposed by the bending element system to test $G_{\max }$. (2) Strain control: the control variable method is used to apply the dynamic load by controlling the dynamic strain method. Between two adjacent sets of cyclic shear vibration intervals, the shear wave velocity, residual pore pressure, and residual strain of soft clay are measured. The test is set based on short-term vibration interval (1-minute pause). Based on the actual occurrence of earthquakes, the loading frequency is chosen as $0.02 \mathrm{~Hz}$, and 50 test points are recorded per cycle during the test (data is collected with 0.02 -second sampling rate). Table 3 provides the details of the loading test method. 


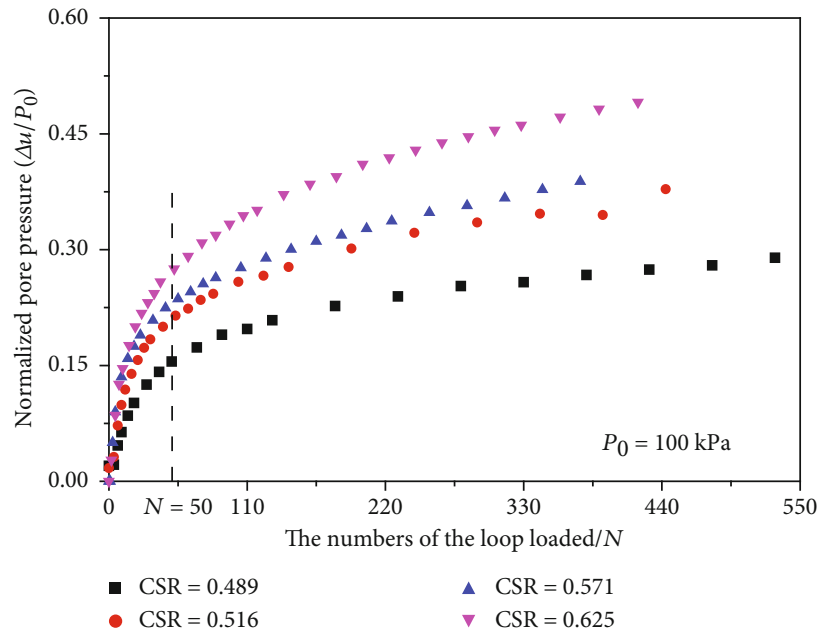

(a)

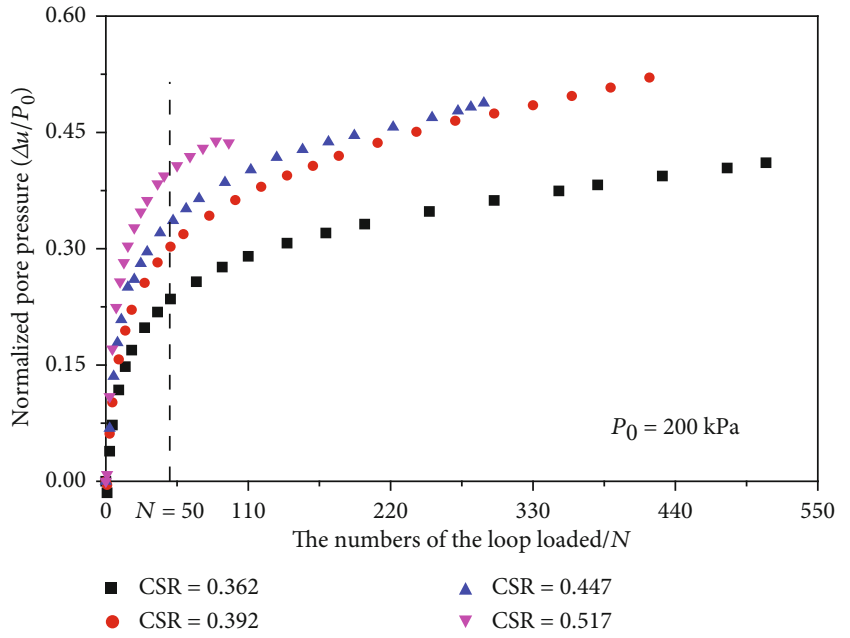

(b)

Figure 9: Pore pressure development curves when confining stress is $100 \mathrm{kPa}$ and $200 \mathrm{kPa}$.

Because of its structure, expectedly, intact soft clay has a nonlinear feature between its strength and confining stress. Moreover, dynamic characteristic of soft clay varied significantly under the same confining stress. To analyze the dynamic stress levels and characteristics under different confining stresses, it was expressed by the CSR in the test, i.e., $\mathrm{CSR}=q_{\mathrm{cyc}} / q_{f}$, where $q_{\mathrm{cyc}}$ is the imposed dynamics stress and $q_{f}$ is the shear strength under static conditions [31]. The samples are submitted to cyclic loading characterized by a sine wave. The total axial strain generated has stress amplitude of $q_{\text {cyc }}$, and a total axial strain of $\varepsilon_{a, t}$ is generated under cyclic loading. During the unloading process, part of the axial strain is called the rebound strain and is denoted by $\varepsilon_{a, r}$. However, the remaining part cannot be recovered, and it is accumulated with the increase of cycles, which is defined by the cumulative strain $\varepsilon_{a, p}$. The total strain is computed as $\varepsilon_{a, t}=\varepsilon_{a, r}+\varepsilon_{a, p}$. The curves of biaxial cycling obtained from the triaxial test results are depicted as in Figure 6.

\subsection{Dynamic Characteristics under Different CSRs}

4.2.1. Strain-Pore Pressure Curves. Figure 7 depicts the change of axial strain change over time at $200 \mathrm{kPa}$ and 0.392 (CSR), respectively. The tensile strain and compressive strain increased linearly, rapidly, under cyclic load as time increased, and the rebound strain also increased sharply. With the increasing number of cyclic loads, the samples continued to soften until they reached the state of failure. In the meantime, $G_{\max }$ continuously decreased.

For the confining stress of $100 \mathrm{kPa}$ and $200 \mathrm{kPa}$, the curves of dynamic strain and different CSRs are illustrated in Figure 8. The dynamic strain developed faster and faster with the increasing loading cycles, which indicates an exponential growth relationship. Under the constant confining stress, when the CSR was small, the strain increased very slowly. As the confining stress increased, the CSR gradually decreased, which resulted in an earlier exponential growth.
Similarly, when the dynamic strength was large enough, the samples crossed the vibration-shearing stage and directly entered the vibration-destructive stage. In this case, the cyclic flow occurred and the dynamic strain increased approximately linearly.

Figure 9 shows the pore pressure development curves when the confining stress was $100 \mathrm{kPa}$ and $200 \mathrm{kPa}$, respectively. When the number of the loop loaded was small, the pore pressure increased rapidly and almost linearly. As the cycles increased, the increase in pore pressure slowed down and finally stabilized. The pore pressure increased with increasing CSR at $100 \mathrm{kPa}$ (Figure 9(a)). The inflection points happened around 50 cycles, which was considered the boundary between linear and nonlinear processes. The pore pressure revealed the same growth law at $200 \mathrm{kPa}$ (Figure 9(b)).

4.2.2. Stress-Strain Relationships. When the confining stress is $200 \mathrm{kPa}$, stress-strain hysteresis loops of four different cyclic stress ratios $(0.362,0.392,0.447$, and 0.512$)$ are shown in Figure 10. Some of the hysteresis loops are labeled in Figure 10. Each group is loaded with a stress control mode. Therefore, local stress is fixed when the loop loads.

One can observe three notable features in Figure 10: (1) The axial strain developed slowly when the number of loop loaded was small (no more than ten). The axial strain increased rapidly with increasing cycles. For $\mathrm{CSR}=0.392$, the strain values corresponding to the 10th, 100th, 200th, and 400 th laps were $18 \%, 30 \%, 42 \%$, and $60 \%$, respectively. Similarly, the area of the hysteresis loop also increased. (2) The strain value increased rapidly with the increase of the CSR. The strain corresponding to the 10th lap increased slightly by $0.432 \%, 0.619 \%, 0.776 \%$, and $1.346 \%$ in the case of CSR of $0.362,0.392,0.447$, and 0.512 , respectively. (3) In the case of a small cyclic stress ratio such as $\operatorname{CSR}=0.362$, the resulting tensile strain and compressive strain were almost equal to the area of the hysteresis loop. For a larger cyclic stress ratio such as CSR $=0.447$ or 0.512 , the tensile 

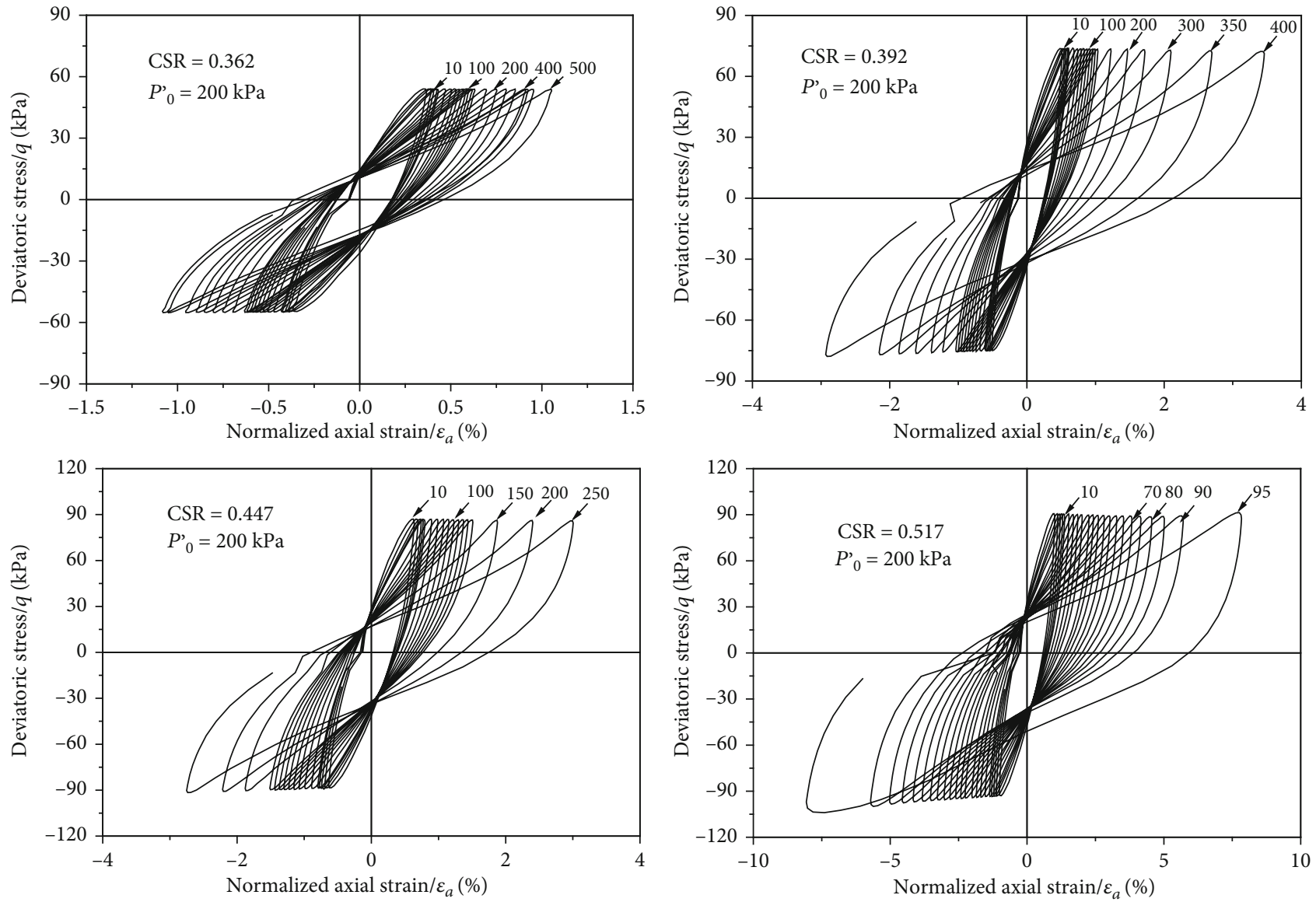

FIgURE 10: Stress-strain hysteresis loops at different CSRs when confining stress is $200 \mathrm{kPa}$.
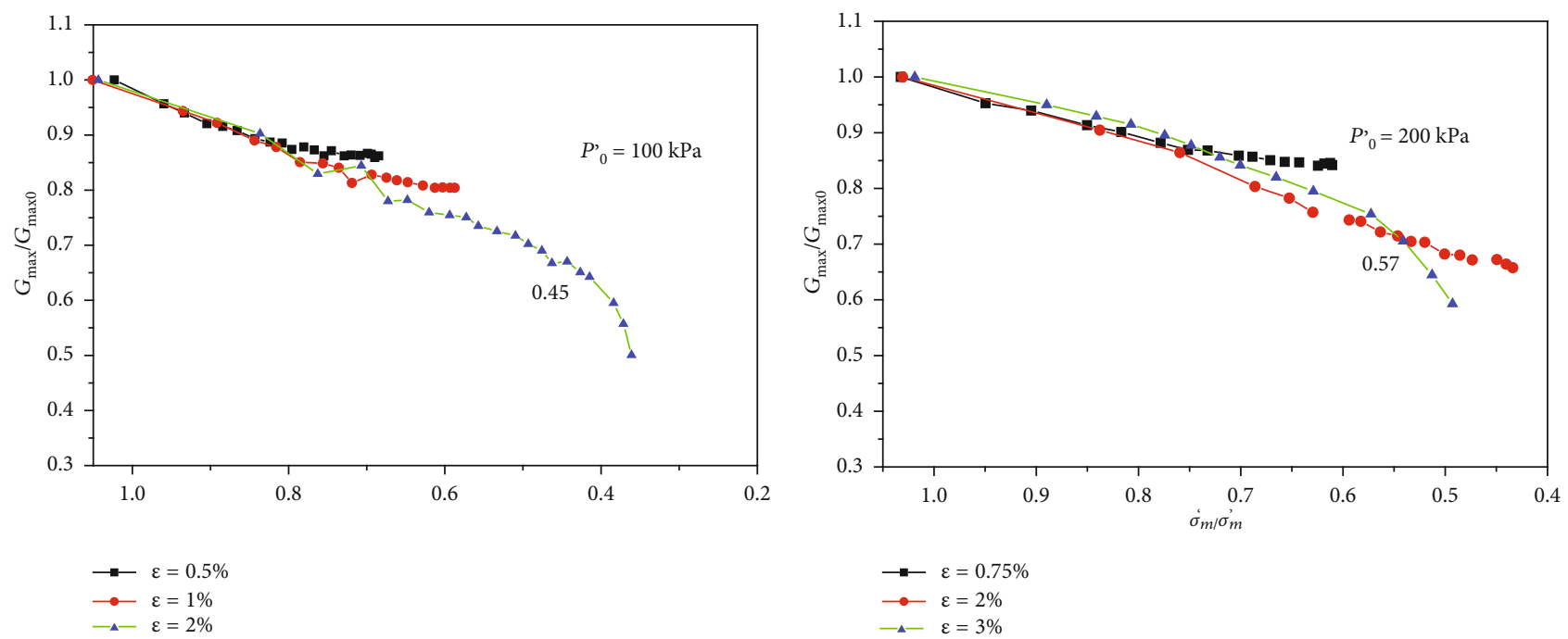

Figure 11: The change of $G_{\max }$ under constant strain.

strain developed faster and the compressive strain developed relatively slowly, which was reflected in the shape of the hysteresis loop. The area enclosed by the tensile half-circle was greater than that of the compressed half-circle. It indicated that the tensile capacity was worse than its compressive capacity. Therefore, it was concluded that the tensile strain was more important than the compressive strain for various CSRs and dynamic stresses.

4.3. Factors Influencing the Attenuation of $G_{\max }$. The attenuation of $G_{\max }$ is usually caused by joint action of both effective stress and dynamic strain. However, the dominant 


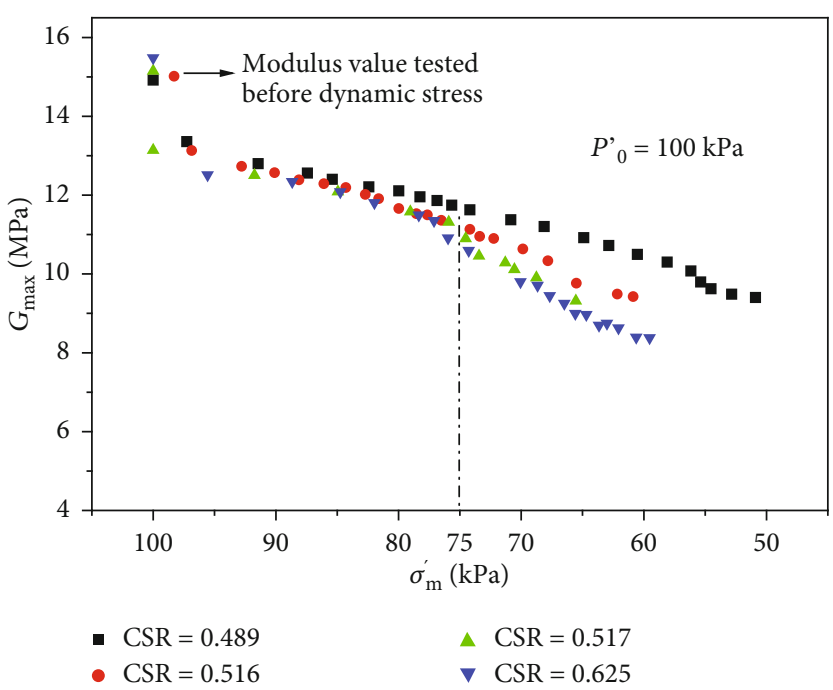

(a)

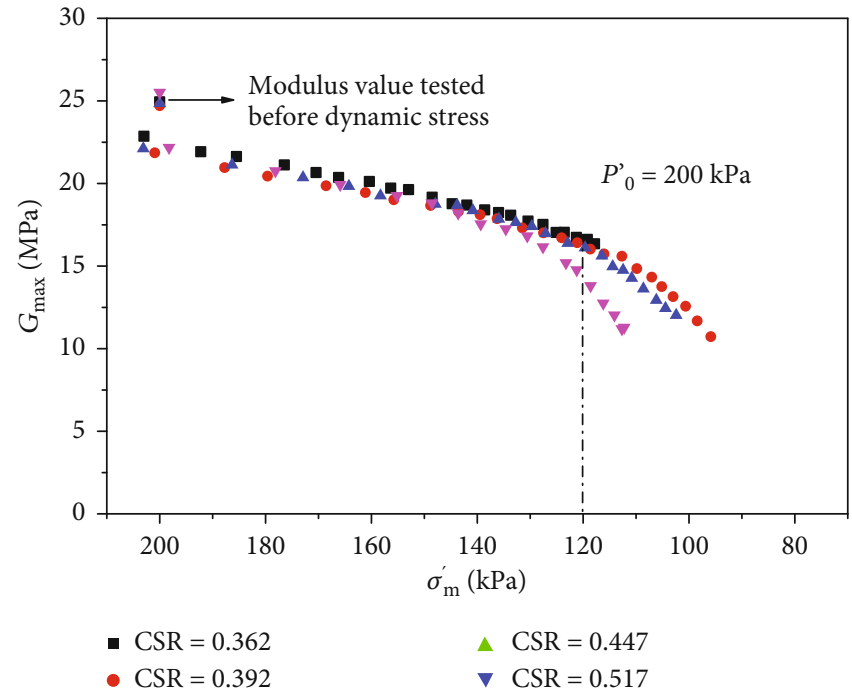

(b)

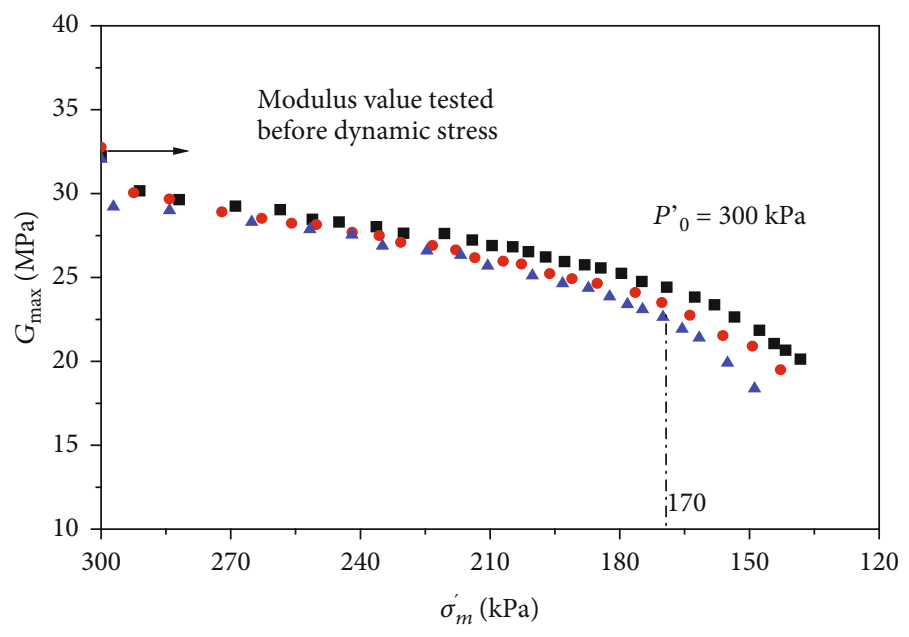

- $\operatorname{CSR}=0.432$

- $\operatorname{CSR}=0.472$

A $\operatorname{CSR}=0.569$

(c)

FIGURE 12: Effect of cyclic loading history on $G_{\max }$ under different confining stresses: (a) $100 \mathrm{kPa}$; (b) $200 \mathrm{kPa}$; (c) $300 \mathrm{kPa}$.

factors are not clearly known. To clearly understand the main reason for the abrupt change, the failure mechanism of soft clay is experimentally studied using a strain-controlled test. The test is conducted in 100 and $200 \mathrm{kPa}$ to cycle the intact soft clay until damage to the structure of the soil. Figure 11 shows the normalized relationship curves between $G_{\max }$ and effective stress.

As can be seen in Figure 11, $G_{\max }$ decreased when effective stress decreased under a constant strain control. However, the single strain value at $100 \mathrm{kPa}$ was insignificant $(\varepsilon=0.5 \%, 1 \%)$. When the effective stress decreased, $G_{\max }$ gradually stabilized. Soft had not yet reached the full failure state. When $\varepsilon$ was $2 \%, G_{\max }$ decreased with respect to the decreasing effective stress. Then, the attenuation amplitude increased until the final failure happened. When the failure strain of the samples did not happen, the modulus decreased as the effective stress decreased during the cyclic loading. Eventually, it stabilized and did not fail. Once the strain reached or exceeded the failure strain, the modulus decreased with respect to the decreasing effective stress. When confining stress was $200 \mathrm{kPa}, G_{\max }$ and the effective stress revealed the same change law. The results showed that the increase of dynamic strain will weaken the interaction between the soil particles, which will lead to the decay of $G_{\max }$. The continuous development of dynamic strain is the main reason for this attenuation [31].

4.4. Failure Criteria of Intact Saturated Soft Clay on the basis of $G_{\max }$. At $100 \mathrm{kPa}, 200 \mathrm{kPa}$, and $300 \mathrm{kPa}$, the law of the effect of cyclic loading history on $G_{\max }$ is plotted in Figure 12.

As can be seen, $G_{\max }$ was $10 \%$ to $15 \%$ greater than the measured modulus after the cyclic load, as it had been shown 


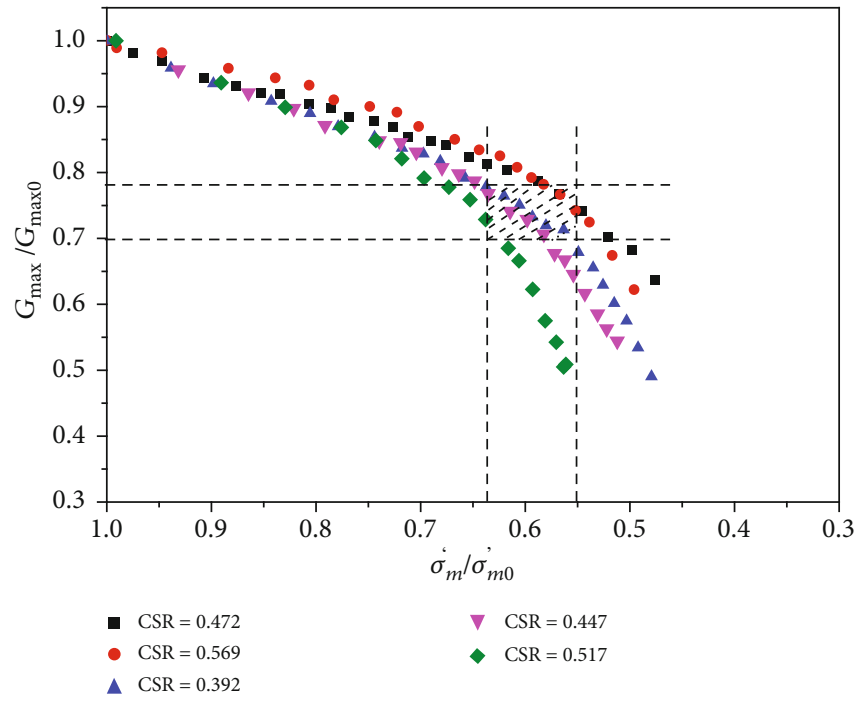

FIGURE 13: Determined failure criterion area of intact soft clay based on $G_{\max }$.
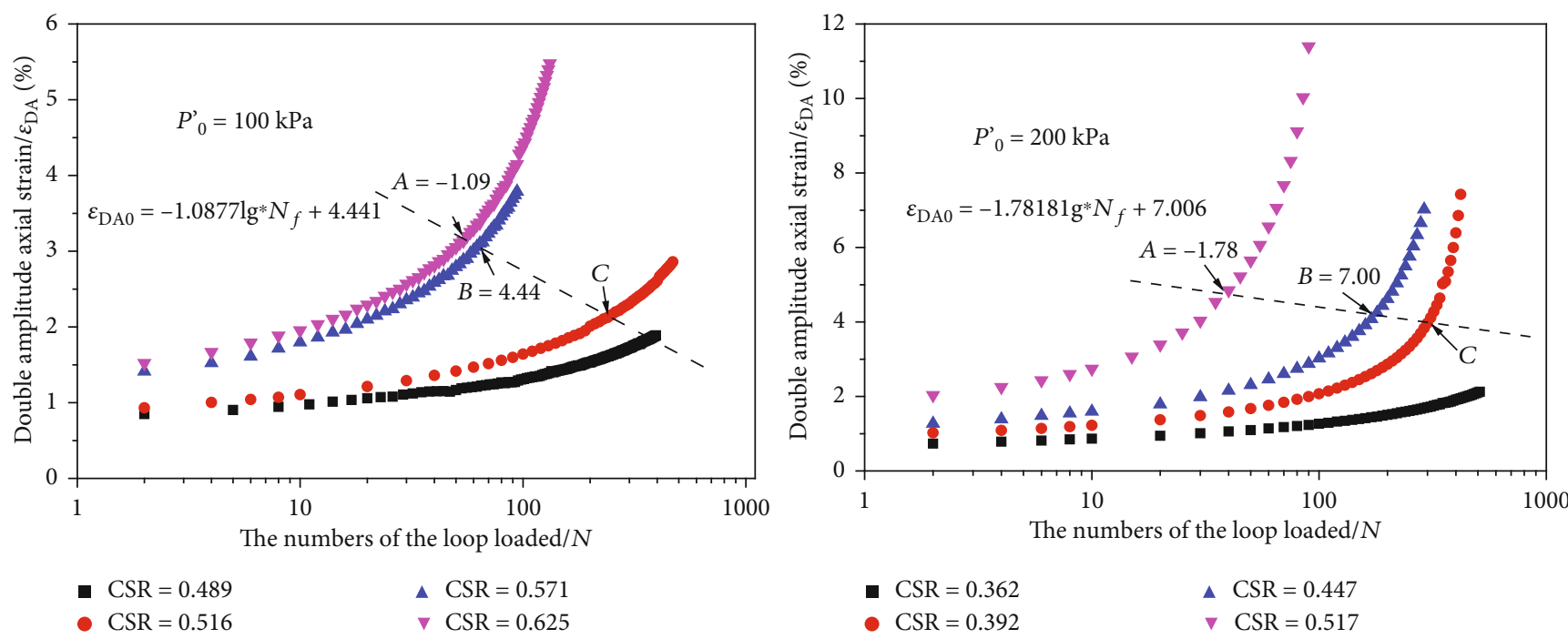

FIGURE 14: Failure criteria on the basis of double-amplitude dynamic strain.

by Cho [33]. The external force caused the disturbance of the soil structure, and the position and the contact force of the soil particles were changed. Moreover, the soil structure was destroyed when the effective stress decreased. It was difficult to restore the soil structure and strength in a short time, as it had been shown by Wichtmann and Triantafyllidis [34]. Furthermore, at the initial stage of the dynamic test, $G_{\max }$ was almost constant and only showed a slight linear decline (in the range 22-25\%). When the effective stress reached $75 \mathrm{kPa}$ (Figure $12(\mathrm{a})), 120 \mathrm{kPa}$ (Figure $12(\mathrm{~b})$ ), and $170 \mathrm{kPa}$ (Figure 12(c)), $G_{\max }$ decreased rapidly. This happens at a point where the soil is greatly deformed, i.e., the failure point. As can be seen, the failure point was not a fixed value under different CSRs. As the cyclic stress ratio increased, the failure point appeared earlier. The larger the CSR, the greater the effective confining stress corresponding to the failure point.
The normalized $G_{\max } / G_{\max 0}$ values and the normalized effective stress $\sigma_{m} / \sigma_{m 0}$ values are plotted in Figure 13 . $G_{\max 0}$ and $\sigma_{m 0}$ represent the initial small-strain modulus and the initial effective stress, respectively. It shows a good correlation between the normalized $G_{\max }$ and the normalized effective stress $\sigma_{m}$. The effective confining stress has a small impact on $G_{\max }$ of saturated soft clay. Similarly, the rectangular area of failure points can be easily obtained. This area was concentrated in the normalized effective stress $\sigma_{m}{ }^{\prime} / \sigma_{m 0}{ }^{\prime}$ from 0.56 to 0.64 and the normalized $G_{\max } / G_{\max 0}$ from 0.72 to 0.78 . This analysis demonstrates that $G_{\max }$ can reflect the change and the failure of the soil structure. Figure 14 indicates the change laws between the strain $\varepsilon_{\mathrm{DA}}$ and the numbers of the loop loaded in this test. When confining stress was $100 \mathrm{kPa}$ and $200 \mathrm{kPa}$, the turning points of various CSRs could be connected by a line. The test results were in agreement with Zhao et al. [31, 35, 36]. 
By applying the cyclic loading, we found that the turning point of the double-amplitude strain of soft clay structure destruction was not constant, but it was closely related to the load amplitude. The double-amplitude strain value will increase with the increase of dynamic stress amplitude. The greater the dynamic stress amplitude, the earlier the corresponding turning point occurs. Moreover, these turning points are basically distributed on a straight line. The test results were in agreement with References [33, 37-39].

From Figure 14, we can draw the inference that $G_{\max }$ can characterize the destruction of soft clay. The turning points of soft clay strain were basically on the same straight line, and the linear equation was basically consistent with the soft clay destruction criterion proposed by Cho [33]. It is represented by the following formula:

$$
\varepsilon_{\mathrm{DA} 0}=A \times \lg N_{f}+B,
$$

where $\varepsilon_{\mathrm{DA} 0}$ is the corresponding strain value at the strain turning point and $N_{f}$ is the vibration corresponding to the turning point.

Therefore, we concluded that making use of $G_{\max }$ as a criterion to assess the failure of soft clay was basically consistent with the commonly used strain failure standards. Compared with the commonly used failure standards, the principle of $G_{\max }$ was more intuitive and convenient. $G_{\max }$ can also reveal the characterization of the saturated soft clay. The increased dynamic strain and the decreased effective stress changed the soil structure and resulted in the attenuation of $G_{\max }$. A point with a fast change in $G_{\max }$ will eventually appear as the failure of soil.

\section{Conclusions}

In this paper, the dynamic triaxial joint bending element test and the resonance column test were conducted for saturated soft clay in the southeast coast of China to investigate the interaction between $G_{\max }$ and soft clay mechanical parameters. The main conclusions obtained from the tests are refined in the following.

(1) The larger the CSR, the smaller the effective stress reduction, and the earlier the occurrence of exponential growth. The increase in pore pressure is consistent with the trend of strain development. The failure points are not the same for different CSRs. The larger the CSRs, the earlier the occurrence of the failure point

(2) The rectangular area of failure points was drawn in this paper, which it defined by normalized effective stress $\sigma_{m}{ }^{\prime} / \sigma_{m 0}{ }^{\prime}$ from 0.56 to 0.64 and the normalized $G_{\max } / G_{\max 0}$ from 0.72 to 0.78 . Under strain control, the sudden drop of $G_{\max }$ reflects the broken structure of the saturated soft clay. Therefore, we can use $G_{\max }$ as an intuitive and easy-to-use parameter to judge the failure of soft clay

(3) A short pause causes a small increase of 1-2\% in $G_{\max }$ and pore pressure. The curves of pore pressure and strain were smooth and continuous

\section{Abbreviations}

\begin{tabular}{|c|c|}
\hline$G_{\max }:$ & Small-strain shear modulus \\
\hline$G_{\max 0}:$ & Initial small-strain shear modulus \\
\hline CSR: & Cyclic stress ratio \\
\hline OCR: & Overconsolidation ratio \\
\hline VCP: & Variable confining stress \\
\hline$\rho:$ & Density of soft clay \\
\hline$\omega:$ & Water content \\
\hline$e:$ & Void ratio \\
\hline$\omega_{p}:$ & Plastic limit \\
\hline$\omega_{L}:$ & Liquid limit \\
\hline$I_{p}:$ & Plasticity index; $I_{p}=\omega_{p}-\omega_{L}$ \\
\hline$P_{c}:$ & Clay content \\
\hline$F_{c}:$ & Fine content \\
\hline$\varepsilon_{a}:$ & Axial strain \\
\hline$q:$ & Deviatoric stress \\
\hline$q_{f}:$ & Peak deviatoric stress \\
\hline$\sigma_{1}^{\prime}:$ & Effective major principal stress \\
\hline$\sigma_{3}{ }^{\prime}:$ & Effective minor principal stress \\
\hline$\sigma_{m}:$ & Effective confining stress \\
\hline$\sigma_{m}^{\prime}:$ & Effective mean confining stress \\
\hline$\sigma_{m 0}^{\prime}{ }^{\prime}:$ & Initial effective mean confining stress \\
\hline$B:$ & Pore pressure coefficient \\
\hline$P_{0}{ }^{\prime}:$ & Initial confining pressure \\
\hline$N:$ & The numbers of the loop loaded \\
\hline$N_{f}:$ & Vibration corresponding to the turning point \\
\hline$q_{\text {cyc }}:$ & Imposed dynamic stress \\
\hline$\varepsilon_{a, p}:$ & Cumulative strain \\
\hline$\varepsilon_{a, t}:$ & Total axial strain \\
\hline$\varepsilon_{a, r}:$ & Rebound strain \\
\hline$\varepsilon_{\mathrm{DA}}:$ & Double amplitude of cyclic axial strain \\
\hline$\varepsilon_{\mathrm{DA} 0}:$ & $\begin{array}{l}\text { Strain value that corresponds to the turning } \\
\text { point of the strain }\end{array}$ \\
\hline$u:$ & Pore water pressure \\
\hline$\Delta \mu:$ & Excess pore water pressure \\
\hline$\delta u:$ & Excess pore water pressure \\
\hline$t:$ & Elapsed time $(s)$ \\
\hline$t_{1}, t_{2}:$ & $\begin{array}{l}\text { Any two time nodes in the secondary consoli- } \\
\text { dation phase after the completion of the main } \\
\text { solidification }\end{array}$ \\
\hline$\Delta G:$ & The modulus changes from $t_{1}$ to $t_{2}$ \\
\hline$G_{1000}:$ & $\begin{array}{l}\text { Shear modulus measured when the confining } \\
\text { stress is applied } 1000 \mathrm{~min}\end{array}$ \\
\hline$I_{G}:$ & $\begin{array}{l}\text { Expression of long-term time effects defined by } \\
\text { modulus changes to time ratios }\end{array}$ \\
\hline$N_{G}:$ & $\begin{array}{l}\text { Expression of long-term time effects defined by } \\
\text { the relationship between normalized modulus } \\
\text { and time }\end{array}$ \\
\hline$\sigma_{m}^{\prime} / \sigma_{m 0}{ }^{\prime}:$ & Normalized effective stress \\
\hline$G_{\max } / G_{\max 0}:$ & Normalized shear modulus. \\
\hline
\end{tabular}

\section{Data Availability}

All data supporting this study are included within the article. 


\section{Conflicts of Interest}

The authors declare no conflict of interest.

\section{Acknowledgments}

This research was financially supported by the National Basic Research Program of China (973 Program) (Grant No. 2015CB057903), Fundamental Research Funds for the Central Universities, and Postgraduate Research \& Practice Innovation Program of Jiangsu Province (Grant Nos. 2019B74214 and SJKY19_04533). The authors express their sincere thanks for the above financial supports.

\section{References}

[1] A. Khosravi and J. S. Mccartney, "Impact of hydraulic hysteresis on the small-strain shear modulus of low plasticity soils," Journal of Geotechnical and Geoenvironmental Engineering, vol. 138, no. 11, pp. 1326-1333, 2012.

[2] V. Jovcic, The Measurement and Interpretation of Small Strain Stiffness of Soils, City Univ, London, 1997.

[3] S. MC, Factors Affecting the Initial Stiffness and Stiffness Degradation of Cohesive Soils, Massachusetts Institute of Technology, 1999.

[4] S. MD, Seismic Assessment of Buildings in Hong Kong with Special Emphasis on Displacement-Based Approaches, The University of Hong Kong, 2005.

[5] P. AJ, M. RS, and N S, Deep Soil Mixing Technology for Mitigation of Pavement Roughness, F. Stud, 2008.

[6] A. Shrestha, A. Jotisankasa, S. Chaiprakaikeow, S. Pramusandi, and S. Nishimura, "Determining shrinkage cracks based on the small-strain shear modulus-suction relationship," Geosciences, vol. 9, no. 9, p. 362, 2019.

[7] C. R. I. Clayton, "Stiffness at small strain: research and practice," Géotechnique, vol. 61, no. 1, pp. 5-37, 2011.

[8] N. K. Psyrras and A. G. Sextos, "Safety of buried steel natural gas pipelines under earthquake-induced ground shaking: a review," Soil Dynamics and Earthquake Engineering, vol. 106, no. 1, pp. 254-277, 2018.

[9] M. Hyodo, K. Yasuhara, and K. Hirao, "Prediction of clay behaviour in undrained and partially drained cyclic triaxial tests," Soils and Foundations, vol. 32, no. 4, pp. 117-127, 2008.

[10] A. Hyde, K. Yasuhara, and K. Hirao, "Stability criteria for marine clay under one-way cyclic loading," Journal of Geotechnical Engineering, vol. 119, no. 11, pp. 1771-1789, 1993.

[11] H. Y. Lei, J. J. Liu, and H. F. Huo, Experimental Study on Dynamic Properties of Structural Soft Clay with Different Stress Level, Northwest. Seismol. J, 2011.

[12] X. Z. Shi, D. S. Yu, E. D. Warner et al., "Cross-reference system for translating between genetic soil classification of China and soil taxonomy," Soil Science Society of America Journal, vol. 70, no. 1, pp. 78-83, 2006.

[13] D. J. Shirley and L. D. Hampton, "Shear-wave measurements in laboratory sediments," The Journal of the Acoustical Society of America, vol. 63, no. 2, pp. 607-613, 1978.

[14] A. Thammathiwat and W. Chim-Oye, Behavior of Strength and Pore Pressure of Soft Bangkok Clay under Cyclic Loading, oye, 2004.

[15] T. T. Nhan, H. Matsuda, and H. Sato, "A model for multidirectional cyclic shear-induced pore water pressure and set- tlement on clays," Bulletin of Earthquake Engineering, vol. 15, no. 7, pp. 2761-2784, 2017.

[16] D. Zekkos, A. Athanasopoulos-Zekkos, J. Hubler, X. Fei, and W. A. Marr, "Development of a large-size cyclic direct simple shear device for characterization of ground materials with oversized particles," Geotechnical Testing Journal, vol. 41, no. 2, p. 20160271, 2018.

[17] A. Lovera, S. Ghabezloo, J. Sulem, M. F. Randolph, and E. Palix, "Pile response to multi-directional lateral loading using P - y curves approach," Géotechnique, vol. 77, no. 4, pp. 288-298, 2020.

[18] S. S. Kumar, A. M. Krishna, and A. Dey, "Assessment of dynamic response of cohesionless soil using strain-controlled and stress-controlled cyclic triaxial tests," Geotechnical and Geological Engineering, vol. 38, no. 2, pp. 1431-1450, 2020.

[19] C. E. Johnson and A. C. Bailey, "A shearing strain model for cylindrical stress states," Transactions of the ASABE, vol. 62, no. 1, pp. 884-888, 2019.

[20] R. J. Cho and W. F. Inno, "Stress-strain responses of block samples of compressible Chicago glacial clays," Journal of Geotechnical and Geoenvironmental Engineering, vol. 136, no. 1, pp. 178-188, 2010.

[21] P Z, Experimental Study on Small Strain Shear Modulus Characteristics of Soft Clay Based on Stress History and Time Effect, Hohai University, 2013.

[22] J. U. Youn, Y. W. Choo, and D. S. Kim, "Measurement of small-strain shear modulusGmaxof dry and saturated sands by bender element, resonant column, and torsional shear tests," Canadian Geotechnical Journal, vol. 45, no. 10, pp. 1426-1438, 2008.

[23] C. Murillo, M. Sharifipour, B. Caicedo, L. Thorel, and C. Dano, "Elastic parameters of intermediate soils based on benderextender elements pulse tests," Soils Found. -Tokyo, vol. 51, no. 4, pp. 637-649, 2011.

[24] B. Song, A. Tsinaris, A. Anastasiadis, K. Pitilakis, and W. Chen, "Small-strain stiffness and damping of Lanzhou loess," Soil Dynamics and Earthquake Engineering, vol. 95, pp. 96-105, 2017.

[25] M. K. Darabi, R. Kola, D. N. Little, E. Rahmani, and N. Garg, "Predicting rutting performance of flexible airfield pavements using a coupled viscoelastic-viscoplastic-cap constitutive relationship," Journal of Engineering Mechanics, vol. 145, no. 2, p. 04018129, 2019.

[26] M. S. Aggour and J. X. Zhang, "Degradation of sands due to combined sinusoidal loading," J. Geotech. Geoenvironmental Eng., vol. 132, no. 12, pp. 1628-1632, 2006.

[27] H. Matsuda, T. T. Nhan, and R. Ishikura, "Prediction of excess pore water pressure and post-cyclic settlement on soft clay induced by uni-directional and multi-directional cyclic shears as a function of strain path parameters," Soil Dynamics and Earthquake Engineering, vol. 49, pp. 75-88, 2013.

[28] C. Zhang, Z. Zhu, S. Zhu et al., "Nonlinear creep damage constitutive model of concrete based on fractional calculus theory," Materials (Basel), vol. 12, no. 9, 2019.

[29] E. T. Bowman and K. Soga, "Mechanisms of setup of displacement piles in sand: laboratory creep tests," Canadian Geotechnical Journal, vol. 42, no. 5, pp. 1391-1407, 2011.

[30] G. L, Cyclic Triaxial Test to Measure Strain-Dependent Shear Modulus of Unsaturated Sand, Zhejiang University, 2013.

[31] C. Gu, Z. Gu, Y. Cai, J. Wang, and Q. Dong, "Effects of cyclic intermediate principal stress on the deformation of saturated 
clay," Journal of Geotechnical and Geoenvironmental Engineering, vol. 144, 2018.

[32] M. X. Ji, The Test of the Curved Meta-Shear Wave Velocity of Piezoelectric Ceramics and the Study of the Dynamic Characteristics of the Saturated Ocean Soft Soil, Zhejiang University, 2005.

[33] W. J. Cho, Recent stress history effects on compressible Chicago glacial clay, Diss. Theses - Gradworks, 2007.

[34] T. Wichtmann and T. Triantafyllidis, "Influence of a cyclic and dynamic loading history on dynamic properties of dry sand, part I: cyclic and dynamic torsional prestraining," Soil Dynamics and Earthquake Engineering, vol. 24, no. 2, pp. 127-147, 2004.

[35] S. Zhao, D. M. Zhang, and H. W. Huang, "Deep learning-based image instance segmentation for moisture marks of shield tunnel lining," Tunnelling and Underground Space Technology, vol. 95, p. 103156, 2020.

[36] S. Zhao, M. Shadabfar, D. Zhang, J. Chen, and H. Huang, "Deep learning-based classification and instance segmentation of leakage-area and scaling images of shield tunnel linings," Structural Control and Health Monitoring, vol. 28, no. 6, 2021.

[37] J. I. Mei-Xiu and Y. M. Chen, "Effect of accumulated pore pressure on shear modulus G_(max) of saturated fine sand during undrained cyclic loading," Rock and Soil Mechanics, vol. 26, no. 6, pp. 884-888, 2005.

[38] Z. Zhu, C. Zhang, S. Meng, Z. Shi, S. Tao, and D. Zhu, “A statistical damage constitutive model based on the Weibull distribution for alkali-resistant glass fiber reinforced concrete," Materials (Basel), vol. 12, no. 12, p. 1908, 2019.

[39] S. Pandya and A. Sachan, "Experimental studies on effect of load repetition on dynamic characteristics of saturated Ahmedabad cohesive soil," International Journal of Civil Engineering, vol. 17, no. 6, pp. 781-792, 2019. 